\title{
Karatê: uma arte marcial para disciplina, distanciamento e autocontrole
}

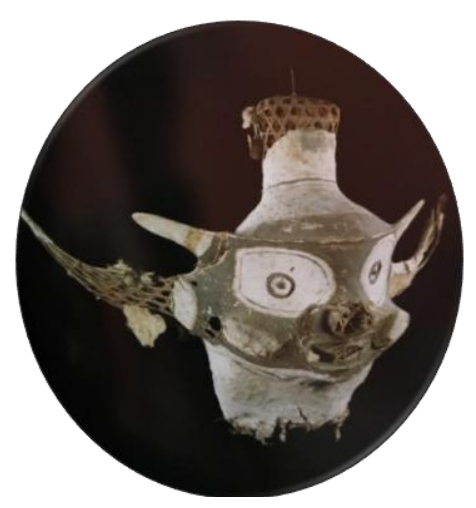

Antônio Lima Pinto 1

Gláucio Campos Gomes de Matos2

\begin{abstract}
Resumo
O presente artigo tem como objetivo destacar a associação da experiência profissional de mais de 45 anos como artista marcial com a teoria eliasiana. Detentor do $5^{\circ}$ Dan (grau) de Karatê (técnicas de mãos vazias) e do $3^{\circ}$ Dan de Kobu-Do (caminho da luta com armas antigas de Okinawa/Japão), apresentamos neste trabalho, a experiência de campo com a teoria do processo civilizador. Vimos, in locu, que o Karatê, sob normas e preceitos filosóficos, é uma arte marcial que muda comportamento e disciplina o indivíduo, contribuindo para o autocontrole, contenção das pulsões e o distanciamento do praticante de artes marciais, no contexto da sociedade manauara/AM.
\end{abstract}

Palavras-chave: Autocontrole; Distanciamento; Artes marciais/Karatê.

\begin{abstract}
This article aims to highlight the association of field practice with theory. Holder 5th Dan (degree) Karate (technical empty) and 3rd Dan Kobu-Do (way of fighting with old weapons from Okinawa/Japan), with over 45 years as a martial artist, presented in this work, field experience with the theory of the civilizing process. We saw, in locu, that karate under norms and philosophical principles, is a martial art that changes behavior and discipline the individual, contributing to selfcontrol, restraint of drives and the distancing of the martial arts in the context of manauara society/AM.
\end{abstract}

Keywords: Self-control; Distancing; Martial Arts/Karate.

${ }^{1}$ Graduado Bacharel em Biblioteconomia pela Universidade Federal do Amazonas (UFAM); Pós-Graduado Especialista em Metodologia do Ensino Superior (UFAM); e Mestrando do Programa de Pós-Graduação Sociedade e Cultura na Amazônia (PPGSCA/UFAM).

2 Prof. da UFAM. Prof. do Programa de Pós-Graduação Sociedade e Cultura na Amazônia (PPGSCA/UFAM). 


\section{INTRODUÇÃO}

As artes marciais, com destaque e ênfase para o Karatê, enquanto esporte institucionalizado e agora olímpico, se caracteriza como uma das modalidades de lutas que, com suas normas inerentes, seus princípios filosóficos e atualmente, amparado pela sustentação científica, pode proporcionar benefícios fisiológicos, psicológicos e sociais ao praticante.

Do ponto de vista da preparação do indivíduo, o praticante sob orientação adequada do Sensei (título honroso de professor experiente de Karatê), desenvolve o aumento da potência muscular dos seus membros, da força, da resistência e da flexibilidade. Potencializa suas qualidades físicas, tornando-se técnica e fisicamente superior a outro indivíduo nãopraticante. Em outras palavras, torna-se uma arma viva.

Resistênia, hipertrofia muscular, aumento da força associado ao aperfeiçoamento de habilidades de membros superiores, assim como técnicas apuradas de ataques e defesas, tornam o indivíduo praticante, uma arma de guerra, sem precedente.

Num olhar dicotomizado, as mãos do Karateka (praticante de Karatê), seus dedos, punhos, cotovelos, joelhos e pés tornam-se armas de um ser biológico capaz de quebrar tábuas, telhas, coco e outros objetos inanimados, com o uso da técnica (Tameshi-Waza). Imagina o que pode fazer com outro indivíduo. No entanto, esse ser biológico, inserido nos princípios do Karatê, não é para treinar sua natureza, para torná-lo um instrumento de matar, como ocorria em outro período da história. Assim podemos destacar os benefícios psicológicos e sociais proporcionados pela prática do Karatê, dentre eles o auto-controle, controle das emoções, que segundo Norbert Elias (1994), são marcas da direção do processo civilizador da sociedade ocidental.

$\mathrm{Na}$ formação do Estado, segundo Elias (1993), fomos obrigados a conviver uns com os outros. Nesse sentido, o indivíduo inserido na prática do Karatê contemporâneo não é preparado para matar, como o fora outrora; ele é conduzido para mudar suas atitudes, controlar suas pulsões, controlar suas emoções ou seja, o indivíduo é levado a nível de dissernimento intelectual para evitar o agir sob impulsos descontrolados. Isto é que Elias (1998) vai designar de distanciamento. 
Diferentemente como pensa o senso comum, o praticante de karatê não vai se armar de faca, arco e flecha, de nunchaku, espadas, lanças como é próprio de outras artes marciais ou como queira, a arma de fogo. O karateka, após anos de treinamento, torna-se a própria arma. Com o domínio da técnica, sua estrutura natural - braços, pernas, cabeça tornam-se armas, porém a legislação não pode obrigar a extirpação dessas armas do indivíduo, pois isso seria crime, extirpar seus membros. Nenhum indivíduo é obrigado por lei que lhe seja retirado por meio cirúrgico seus braços, pernas ou outras partes do corpo, em outras palavras, o karateka independente de gênero - pode torna-se potencialmente armado e aniquilar o oponente atingindo pontos naturalmente vulneráveis aos moldes do corpo humano.

Porém, e isso não é contraditório no curso do processo civilizador, as normas e os princípios filosóficos do Karatê convergem para a disciplina do indivíduo. Para que esse seja autocontrolado e suprima impulsos de violência. O indivíduo é preparado de corpo e alma para que seja, conforme seu comportamento, aceito socialmente na sociedade manauara ou em qualquer outra sociedade.

\section{AS ARTES MARCIAIS - ORIGENS}

As artes marciais, tiveram suas origens no Oriente, China e Índia, as quais posteriormente foram disseminadas em países como o Japão, Coreia e Sudeste Asiático e, somente depois, para o Ocidente. Nesse sentido, Haward Reid e Michael Croucher, destacam

\footnotetext{
Trata-se evidentemente de um termo ocidental, que deriva do termo latino do planeta Marte, o deus romano da guerra. Foi escrito pela primeira vez em língua inglesa no ano de 1357, por GeoffreChaucer, que se referiu ao "tourney marcial", da época medieval. E, 1430, o termo já era usado em referências ao treinamento para a guerra, aos próprios atos de guerra e também aos esportes. HOWARD; MICHAEL (1983, p. 12).
} 
Para se ter uma ideia de periodicidade, os mesmos autores se referem a achados históricos que remetem ao possível início das artes marciais, conforme se destaca

Pode ser que o testemunho mais antigo da existência das artes marciais, a ser levado em conta com muito cuidado, nos seja dado por duas pequenas peças babilônicas, encontradas por pesquisadores, datadas de entre 3000 e 2000 a.C. Ambas são representações de dois homens lutando. O braço de um deles está na característica posição de bloqueio, que é tão fundamental nas artes marciais modernas. A outra peça consiste numa estatueta de dois homens lutando, cada um dos quais segura o cinto do outro. Trata-se de uma forma rara de luta de agarrar, desconhecida no Ocidente mas muito famosa na luta japonesa chamada sumô. Não há nenhum outro indício de que as artes marciais tenham surgido no Crescente Fértil, mas muitas outras ideias importantes começaram lá e de lá disseminaram-se para o Oriente e o Ocidente. HOWARD; MICHAEL (1983, p. 22).

Por oportuno, registra-se que a região do Crescente Fértil, mencionada pelos autores, engloba as áreas do atual Israel, Jordânia e Líbano, e partes geográficas da Síria, Iraque, Egito e Sudeste da Turquia.

Entretanto, há registros que indicam o nascimento de artes marciais com datas mais antigas. Nesse sentido, segundo BUENO; TORRES (2014, p. 97), a modalidade de luta conhecida por

Sipalki-Do é uma arte marcial tradicional, criada há 4.300 anos pelos mongóis. Das duas principais tribos trilharam caminhos diferentes, uma foi para o Norte, a outra viajou para o Sul da Ásia. Uma delas ocupou a península, que hoje é chamada Corea do Sul. Lá os mongóis introduziram várias artes marciais. 
Como se observa, não há muita precisão no tempo e espaço sobre o efetivo início da prática das artes marciais, em decorrência de poucos ou até pela ausência de material escrito dessas épocas, tendo em vista as informações serem passadas pela oralidade. Há, no entanto, em tempos mais recentes, lendas ou histórias, uma das quais relata que o monge indiano de nome Bodaitara (a pérola da suprema iluminação), em japonês, Daruma (boneco), mas também conhecido por Bodhidharma, que teria desenvolvido um estilo de luta, o Shaolin Kung Fu, no templo budista Shaolin, por volta do século VI. Esta modalidade posteriormente foi disseminada em Okinawa/Japão, então reinado de Ryukyu, no século XVIII, influenciando e contribuindo grandemente com o nascimento e desenvolvimento da já incipiente arte marcial local, o Te (Mão), que era desenvolvido principalmente na cidade de Shuri, mas também em Naha e em Tomari, por isso mesmo, com a junção de técnicas dos dois estilos (o chinês e o okinawano), a modalidade recebeu o nome de To De (Punho da China). Posteriormente, pela necessidade de uma nova configuração local de poder, que representava cada um dos clãs locais, então passou a se chamar Shuri-Te (Mão de Shuri), Naha-Te (Mão de Naha) e Tomari-Te (Mão de Tomari). Depois Okinawa-Te e, finalmente Karatê, no final do século XIX. No início do século XX, com Okinawa já politicamente anexada ao Japão, o Karatê passa a ser praticado oficialmente como esporte institucionalizado no país. Portanto, Karatê é uma arte marcial que teve forte influência do Shaolin Kung Fu chinês, do templo budista de Shaolin.

Daí se originaram vários estilos de Karatê, dentre os quais o Shorin-Ryu, o Shotokan; Shito-Ryu; Goju-Ryu, Wado-Ryu, dentre outros.

\section{A ARTE MARCIAL KARATÊ COMO ESPORTE INSTITUCIONALIZADO E OLÍMPICO}

O Karatê é uma arte marcial de defesa pessoal sem uso de armas, outrora praticada como instrumento de preparação de guerreiros. 
Atualmente é praticada como esporte em vários continentes, onde seus adeptos aprendem uma nova filosofia de vida, na construção de um espírito desenvolvido em um corpo forte. Ressalta-se que o Karatê, depois de anos de reivindicações pelos órgãos dirigentes, foi finalmente uma modalidade aprovada como esporte olímpico pelo Comitê Olímpico Internacional (COI), juntamente com o Comitê Olímpico Brasileiro (COB), durante os Jogos Olímpicos realizados no Brasil (agosto de 2016).

O Karatê contemporâneo, segundo HOWARD; MICHEL (1983, p. 229)

Depois do judô, o grande sistema marcial desarmado que apareceu no Japão foi o Karatê de Okinawa. Em 1921, o príncipe Hirohito, filho do imperador, fez uma visita a Okinawa, onde assistiu a uma demonstração de karatê comandada por FunakoshiGuichin, mestre do karatê ShuriTê [...]. No ano seguinte Funakoshi foi convidado a ir a Tóquio apresentar sua arte à nação japonesa; e partindo dessa origem humilde, seu estilo - depois conhecido como Shotokan, do nome de seu dojô ou salão de treinamento cresceu até se tornar a corrente principal dos caminhos marciais japoneses.

Por oportuno e não menos importante entende-se como pertinente falar do termo esporte (ou desporto), citado no parágrafo anterior, conforme

Muitos tipos de desportos que hoje são praticados, de maneira mais ou menos idêntica, por todo o mundo tiveram origem na Inglaterra. Daqui propagaram-se para outros países, principalmente na segunda metade do século XIX e primeira metade do século XX. O futebol, sob a forma que se tornou conhecido na Inglaterra por Association Footbal ou 
por intermédio da abreviatura popular soccer, foi um deles. Corrida de cavalo, luta, boxe, tênis, caça à raposa, remo críquete e atletismo foram outras formas. $O$ termo sport também foi largamente adotado por outros países como um termo genérico para esse tipo de passatempo. ELIAS; DUNNING (1992 p. 187).

Os estilos de lutas do passado, praticados no Ocidente não possuíam características muito semelhantes com as praticadas na Índia, China ou, posteriormente, às do Japão. O boxe e a luta livre greco-romana eram muito diferentes das praticadas no Oriente, no entanto já se tratava de uma relação de pertinência com as artes marciais.

Nesse contexto, cita-se, por exemplo, o pancrácio, um estilo de luta grego praticada com extremo nível de violência, para o olhar civilizado de nossos dias, era normal a aplicação de uma série de golpes até a morte do adversário, no entanto, permitida em regras pela então Cidade-Estado. Nesse aspecto, Norbert Elias e Eric Dunning enfatizam

No pancrácio o adversário lutava com todas as partes do corpo, as mãos, os pés, os cotovelos, os joelhos, os pescoços e as cabeças; em Esparta usavam mesmo os pés. Os lutadores do pancrácio podiam arrancar os olhos uns dos outros...podiam, também, obstruir, agarrar os pés, narizes e orelhas, deslocar os dedos e braços e aplicar estrangulamentos. No caso de conseguirem derrubar o outro, podiam sentar-se sobre ele e bater-lhe na cabeça, cara e orelha; também podiam dar-lhe pontapés e pisá-lo. Não é preciso dizer que os lutadores desta prova brutal eram atingidos, por vezes, pelos mais terríveis ferimentos e, não raro, morriam. O pancrácio dos jovens efebos era provavelmente o mais brutal de todos. Pausânias, Geógrafo e viajante grego, 115-180 d.C. diz-nos que os lutadores lutavam com unhas e dentes, mordiam e rasgavam os olhos uns dos outros. ELLIAS; DUNNING(1992 p. 201). 
Também pode-se citar o boxe grego, comum ás outras formas de preparação de lutas corporais e praticadas nas cidades-Estado gregas, mas diferente do boxe inglês nos séculos XVIII e XIX, era considerado tanto como um meio de preparação para a guerra como para competições de jogos. Nesse contexto, também estão inseridas as modalidades de lutas dos gladiadores romanos com suas técnicas, que eram realizadas para agradar ao público, que embora violentas para os dias atuais tinham diferença em comparação com as praticadas no Oriente.

A inserção dessa arte marcial no Brasil deve-se, principalmente, ao deslocamento para o país dos mestres japoneses, no começo do século XX. A primeira academia (dojo) a que se tem notícia somente teria sido fundada em 1956, pelo senseiMitsukeHarada, do estilo Shotokan, na cidade de São Paulo. Em seguida também chegaram ao país os mestres Yasutaka Tanaka e SadamuUriu, que se instalaram no Rio de Janeiro; Hiashiro, em Brasília/DF; EisukoOishi, na Bahia; e Yoshihide Shinzato, do estilo Shorin-Ryu, em São Paulo/SP.

Segundo dados da revista Grandes Mestres das Artes Marciais no Brasil (2014, pp. 10/11)

Em 1960, com a criação da Associação Brasileira de Karatê, pelo mestre (Shihan) Akamine, o Karatê experimentou um crescimento importante em todo o país... Yoshihide Shinzato, do estilo Shorin-Ryu, que apesar de ter chagado ao país em 1954, somente fundou seu dojo em 1962, a Academia Santista de Karatê Shorin-Ryu, em Santos/SP que, em 1970 passa a se chamar União OkinawaShorin-Ryu Karatê-Do Brasil, uma das maiores organizações de Karatê do mundo.

Como praticante do Karatê Shorin-Ryu, faixa preta $5^{\circ}$ Dan pela Confederação Brasileira de Karatê (CBK), e faixa preta $3^{\circ}$ Dan de KobuDo (Caminho das técnicas com armas nativas de Okinawa), aluno do saudoso Grão-Mestre YoshihideShinzado, e como o primeiro representante 
do estilo no Amazonas, descrevo o que me foi passado pela oralidade, a história da modalidade.

Para contextualizar um pouco a historicidade, fala-se de forma sucinta, da árvore genealógica do Karate. Os mestres que contribuiram para a criação do Karatê, inclusive do estilo Shorin-Ryu atual, desde o reino Ryukyu até a atual Okinawa, por ordem cronológica foram, respectivamente, Peichin'Takahara, no século XVIII; KangaSakukawa, no início do século XIX; SokomMatsumura, no final do século XIX, seguido de seu aluno, AnkoItosu até o início do século XX.

ChochinChibana (1885-1969), aluno e sucessor de AnkoItosu, fundou oficialmente o estilo Shorin-Ryu (Pequeno Bosque ou Jovem Floresta), nome influenciado pelo templo chinês Shaolin, que tem o mesmo significado. Com sua morte, em 1969, seu aluno Katsuya Miyahira (19182010) deu prosseguimento na direção geral do estilo.

No Brasil, o primeiro representante do estilo Shorin-Ryu, desde a década de 50 foi o grão-mestre Yoshihide Shinzato (1927-2008), que chegou ao país em 1954 e, em 1962 fundou a Associação OkinawaKarateDo Shorin-Ryu (AOKSR) para congregar oficialmente os adeptos locais e, respectivamente a União Shorin-Ryu Karatê-Do Brasil (USRKB) e, em nível internacional, a International Union Shorin-RyuKarate-Do Federation (IUSRKF) para unir a todos os afiliados espelhados não apenas no Brasil, mas também em nível internacional. Para representar sua identidade própria, fundou a Shinshukan (Shin, de Shinzato; Shu, de Yoshihide; e Kan de associação), uma forma de identificar a todos os seus seguidores, mas com um sentido mais profundo que representa um código de postura, princípios e éticas a serem seguidos.

Com a morte de Yoshihide Shinzato, em 13/01/2008, seu filho Masahiro Shinzato, grão-mestre $9^{\circ}$ Dan, assume a direção geral da organização Shinshukan.

Contextualizando, também de forma sucinta, sobre as organizações do Karate, relata-se que a expansão desta arte marcial em níveis internacionais e o crescimento de seus adeptos geraram a necessidade de criação, respectivamente, da União Mundial de Karate-Do Organização, em inglês Wolrd Union Karate-Do Organization (WUKO) e posteriormente da Federação Mundial do Karatê, em inglês 
WolrdKarateFederation (WKF), na década 80, resultou também na formação legal das organizações nacionais e estaduais específicas do Karatê.

No Brasil a organização das entidades do Karatê começou com a legalização das associações desportivas e suas respectivas federações na década de 80, em níveis estaduais e, do órgão dirigente nacional da modalidade, a Confederação Brasileira de Karatê (CBK), fundada em 11 de Setembro de 1987.

Nessa nova configuração, na cadeia de comando hierárquico na teia de interdependência, a autonomia relativa da CBK por vez, passa a ser subordinada às instâncias superiores, como a já citada WKF, e ligada ao Comitê Olímpico Brasileiro (COB), entidade subordinada ao Comitê Olímpico Internacional (COI). Com as organizações do Karatê recémcriadas os atores nelas envolvidos passaram a pleitear a inserção da modalidade nas Olimpíadas, mas também a elas obedecem a uma hierarquia, por conseguinte, sujeitas às ordens superiores, entre as quais a urgente criação e prática de novas normas de arbitragem e aplicação severa de penalidades a infratores, visando principalmente, ao controle dos golpes e das ações resultantes de pulsões agressivas.

\section{OS PRINCÍPIOS ÉTICOS E AS NORMAS DO KARATÊ COADUNADAS COM O CURSO DO PROCESSO CIVILIZATÓRIO}

Com a prática do Karatê, o Karateka aprende os princípios e ideais filosóficos como o respeito; paciência; responsabilidade; sociabilidade; justiça; e contenção das pulsões de agressividade. Assim, diante das exigências de comportamentos socialmente aceitos é que acreditamos no Karatê como um instrumento, uma arte marcial que colabora em moldar o indivíduo, na sua disciplinarização, esteja ele em risco social ou não.

Segundo FUNAKOSHI, Guishin", um Karateka tem como lema: “esforçar-se para a formação do caráter (disciplina); criar um espírito de esforço, de superação (determinação); respeitar acima de tudo (respeito);

${ }^{*}$ Citado por www.academiaparamitta.com 
conter o espírito de agressão (desapego); fidelidade para com o verdadeiro caminho da razão (honra)".

Há de entender que uma arte marcial não existe por si só, sem que esteja ligado a seres humanos que vivem em relação de interdependências. Ela, arte marcial e seus adeptos, não têm autonomia de fazer suas próprias regras, pois ela foi criada por indivíduos que no curso do desenvolvimento da sociedade, foram desenvolvendo regras de boa convivência, procurando extirpar a violência do seu meio.

Portanto, o que se observa no decorrer desse longo processo são os avanços dessas normas, como fortalecimento do código de postura, enquanto princípios éticos e filosóficos da Shinshukan (academia de Yoshihide Shinzato), todos os Karatekas (professores e alunos) devem recitar em voz alta, para sua auto reflexão e cumprimento no dia a dia, antes e ao término dos treinamentos, o Dojo-Kun (conjunto de regras, de ideais filosóficos da academia), que se constitui de cinco preceitos únicos, sem hierarquia, Hitotsu (Primeiro, único):

$1^{\circ}$ - HitotsuReigi $=>$ Respeito acima de tudo, cortesia, etiqueta, educação, demonstrado para todos, inclusive com o gesto de reverência, ao entrar no Dojo (academia), diante do mestre e ao ficar diante do Kamissama (templo);

$2^{\circ}$ - HitotsuShisei $=>$ Sinceridade, autenticidade, generosidade, benevolência;

$3^{\circ}$ - HitotsuDorioku $=>$ Esforço com perseverança para formação do caráter, e para atingir objetivos;

$4^{\circ}$ - HitotsuSekinin $=>$ Responsabilidade, respeito, postura, comportamento adequado em sociedade; e

$5^{\circ}$ - HitotsuMeiro $=>$ Alegria, harmonia, amor.

Esses princípios sociais e ideais filosóficos objetivam que o praticante obtenha umaapreensão, maturidade e autoreflexão para direcionar sua vida e suas atitudes, aperfeiçoando seu comportamento, impondo-lhe autocontrole de suas pulsões violentas. Espera-se um indivíduo consciente e respeito às normas e às leis, para alcançar transformação social e empoderamento. 
O estilo Shorin-Ryu, ou Shinshukan possui um juramento que deve ser recitado e cumprido por todos os seus adeptos. O referido juramento deve ser recitado por todos em voz alta:

Comprometo-me a treinar o Karate-Do com o objetivo de aperfeiçoar uma boa técnica, construir um corpo forte e um espírito bem equilibrado. Honrarei o Karate-Do com dignidade e humildade em qualquer situação. Estarei sempre disposto a lutar com justiça em benefício da ordem e da paz. SHINZATO (2004, p. 11)

$\mathrm{Na}$ teoria eliasiana, especificamente no Processo Civilizador, volume 1, que trata da história dos costumes, vemos que os indivíduos foram se moldando, readequando seus comportamentos em sociedade pela compreensão do que é socialmente entendido como correto, em cumprimento às normas de comportamento em geral. Essa mudança de comportamento decorre, inclusive, do autocontrole de suas pulsões agressivas.

Desta forma, com base na teoria de Norbert Elias, como também na arte marcial Karatê, compreende-se e ratifica-se que há no processo civilizatório uma diversidade de mecanismos direcionadores que conduzem o indivíduo a ser um bom cidadão, por exigência social.

No Koto (espaço de $8 \mathrm{~m}^{2}$, delimitado socialmente e permitido para os indivíduos competirem), sob controle, para que coloquem em prática suas estratégias de ataques, defesas e contra-ataques. No Koto os indivíduos potencializados ficam sob o julgo dos cinco árbitros, um principal central e quatro auxiliares laterais, além do árbitro fiscal, externo ao referido espaço em área contígua, sofrerá penalidade se seu comportamento vier a prejudicar seu oponente. O combate torna-se um espetáculo para o espectador, pela beleza no domínio das habilidades, sem, contudo, aniquilar seu adversário. Ao final, por normas de etiqueta, perdendo ou ganhando, tem que cumprimentar o árbitro principal e o outro competidor, gesto de respeito que também é feito no início da luta.

Por oportuno, ressalta-se que dentre as infrações mais graves em uma competição de Karatê, estão o ato de fingir ter sido atingido pelo oponente, objetivando obter vantagem na pontuação, considerado como ato de desonra ao Karatê; quando um lutador atingir fisicamente o outro 
em partes do corpo proibidas pelas normas, com golpes de pés ou mãos sem controle, causando-lhe danos físicos, resultando em hematomas, fraturas ou derramamento de sangue; as ações de violência simbólica com desrespeito ao oponente, ao árbitro, ou ao público presente na academia ou em eventos oficiais. Ou seja, o que presenciamos é a vigência do processo civilizador que adentra as artes marciais, especificamente o Karatê, com a sua institucionalização, doravante mais rigorosa, em decorrência de sua recente aprovação como esporte olímpico.

Nesse contexto, pela vigência do Estado e por extensão, do processo civilizatório, Foucaut (1977, p. 135), se refere ao espaço geográfico que ofereça uma melhor visualização de indivíduos, para poder vigiá-los e aplicar as normas sobre quem as infringir. Nessa semelhança com o Koto, espaço determinado para as competições de Karatê, entre dois ou mais atletas, sob os atentos olhares dos árbitros acima referidos, os quais registram os pontos ou as infrações dos competidores.

Ainda, conforme o referido autor,

[...] A disciplina exige um espaço específico para seu exercício, um espaço no qual os indivíduos possam ser vigiados nos seus atos, que tenham seu lugar específico para visualizar seu comportamento para poder sancioná-lo ou medir suas qualidades. (FOUCAUT, 1977, p. 135).

Ressalta-se, no caso do Karatê, esse controle disciplinar objetiva que o Karateka aprofunde mais ainda o seu autocontrole sobre suas emoções e pulsões violentas e, por conseguinte, adquira autodomínio e técnica durante o combate, não apenas no espaço do Dojo, mas onde quer que esse indivíduo se faça presente, para que as coerções externas se tornem autocoerção.

Nos casos de ocorrências de atos de indisciplinas e descumprimento das normas com ações resultantes de pulsões violentas, por exemplo, o rigor das normas será aplicado. Para se conhecer a tipologia violência praticada nos esportes, Kurt Weis, citado por Norbert Elias e por Eric Dunning, afirmam 
[...] os tipos de violência praticados por seres humanos nos desportos e em qualquer outro domínio são diversos e complexos. Contudo, parece razoável aceitar que se pode alcançar uma determinada compreensão do problema dando relevo às distinções que possam estabelecer entre as suas formas e dimensões particulares. Distinguirei tipos de violência em termos de a) os meios utilizados; b) os motivos dos atores e os níveis de intencionalidade envolvida; e c) alguns dos parâmetros sociais que contribuem para as formas de violência umas das outras [...]. (ELIAS; DUNNING 1992, p.329).

Assim podemos observar que Kurt Weis apresenta formas de violência humana, relacionando oito distinções provisórias, das quais elencamos cinco nomeadamente, que podem ocorrer durante as disputas desportivas no Karatê.

1) Se a violência é real ou simbólica, isto é, se apresenta a forma de uma agressão física direta ou envolve simplesmente atitudes verbais e/ou atitudes não verbais;

2) Se a violência é intencional ou a consequência acidental de uma sequência de ações que, no início, não tinha a intenção de ser violenta;

3) Se se considerar a violência iniciada sem provocação ou como sendo uma resposta, em retaliação a um ato intencionalmente violento, ou sem a intenção de o ser;

4) Se a violência é legítima no sentido de estar de acordo com as regras, normas e valores socialmente prescritos ou se não é normativa ou ilegítima no sentido de envolver uma infração dos padrões sociais aceitos;

5) Se a violência toma uma forma "racional" ou "afetiva", isto é, se é escolhida de forma racional como um meio de assegurar a realização de um objetivo dado, ou subordinada a "um fim em si mesmo" emocionalmente satisfatório e agradável. Outra forma de conceptualizar esta diferença seria distinguir entre a violência nas formas "instrumentais" e “expressivas.” (ELIAS; DUNNING, 1992, p.330). 
Para um árbitro de Karatê, é de suma importância compreender bem essas distinções, para não confundir ou cometer injustiça no momento de um julgamento e aplicação da norma. Algumas dessas formas específicas de violência se assemelham às ocorridas em uma luta de Karatê, quando há estrapolação do autocontrole ou pela imperícia por um ou por mais competidores.

Desta forma, fazendo um comparativo com as normas de arbitragem do Karatê como julgamento, utilizando os critérios apresentados por Kurt Weis, percebe-se que há uma semelhança no critério de julgamento, para uma efetiva e justa aplicação das penalidades, baseadas nas normas de arbitragem de Karatê, onde o árbitro julga a desenvoltura do atleta procurando evitar falhas técnicas ou subjetividades, e registra os acertos (pontos) ou aplica as penalidades ao lutador que cometer infração.

A esse respeito podemos verificar que

[...] A vigilância quanto ao cumprimento das regras tornou-se mais eficiente; por isso, passou a ser menos fácil fugir às punições devidas a violação das regras. Por outras palavras, sob a forma de 'desportos', os confrontos de jogos envolvendo esforços musculares atingiram um nível de ordem e de autodisciplina nunca alcançados até aí [...]. (ELIAS 1992, p. 224)

Entende-se assim, que a coação exterior não seja aplicada com a violência, mas sim, pela disciplina, pela persuasão, que resulta na autocoação, no autodomínio, exaustivamente exercitada pelo karateka; ela é, portanto, o resultado da conscientização e da interiorização dos cinco preceitos filosóficos do Karatê Shinshukan, acima mencionados, como também das normas de competição, que geram valores, maior aproximação mútua de estima e respeito, no que Elias se referiu como "[..] coações exteriores constantes fundamentadas no calor afetivo, que dá segurança”.

Nesse contexto mencionamos que há uma semelhança, também, na forma de preparação física do atleta de Karatê com os treinamentos para condicionamentos físicos para guerreiros militares.

A aplicação da disciplina é um dos pontos fundamentais para o alcance dos objetivos traçados, quais sejam: a força e a resistência física, as técnicas, a coragem, as posturas, as transformações e moldagens de seus 
corpos e seus comportamentos, durante o século XVIII, referidas por Michel Foucaut, o qual ressalta

[...] O soldado é antes de tudo alguém que se reconhece de longe; que leva os sinais naturais de seu vigor e coragem, as marcas também de seu orgulho: seu corpo é o brazão de sua força e de sua valentia; [...] em qualquer sociedade o corpo está preso no interior de poderes muito apertados, que lhe impões limitações, proibições ou obrigações. Muitas coisas, entretanto, são novas nessas técnicas. [...] Esses métodos que permitem o controle minucioso das operações do corpo, que realizam a sujeição constante de suas forças e lhes impõem uma relação de docilidade, são o que podemos chamar de “disciplinas”. (FOUCAUT, 1987, p. 164/165).

Elias e Eric Dunning, quando se referem aos desportos modernos que, apesar de possuírem características de violentos, seus praticantes aprenderam a controlar as pulsões que geram violência durante uma disputa, na perspectiva do desenvolvimento, no caso, em referência ao boxe, ao râguebi modernos. Assim asseguram

Em contraste com os seus antecessores populares, o râguebi moderno é o exemplo de uma forma de jogo que é civilizada, pelo menos, em relação aos quatro aspectos que estão ausentes nas formas ancestrais. A esse respeito, isso é característico dos modernos confrontos do desporto em geral. (ELIAS; DUNNING, 1992, pp. 335/6).

Nessa particularidade, nos jogos de Karatê, há também uma similitude com o que se referem os autores, concernente, principalmente ao autocontrole das pulsões que geram violência, na perspectiva do desenvolvimento, tendo em vista o paulatino aumento da rigorosidade na aplicação das normas de conduta - desde a prática do Karatê tradicional, onde era permitido mais contato dos golpes no corpo do adversário, até o atual Karatê Olímpico, onde, ao contrário, o contato é mínimo - visando com isso, ao aumento no controle dos golpes, se sobressaindo, por conseguinte, a técnica,ao invés da violência.

Elias e Eric Dunning ressaltam ainda, ao se referirem à aplicação das normas, por parte do árbitro, ajudam a controlar e conter os atos de extrapolação dos impulsos do comportamento dos competidores nos jogos de rugby, por exemplo, ressaltam tratar-se de 
1) Um conjunto de regras escritas, formalmente instituídas, que exigem rigoroso controle quanto ao uso da força física e que a proíbe em relação a certas formas como, por exemplo, placagem de <braço em riste $>$ e $<$ golpes violentes $>$, isto é, dar pontapés num jogador adversário, derrubando-o;

2) Sanções intra jogos claramente definidos, isto é, penalties que podem ocorrer a fim de punir transgressores, e, como sanção última, para violações sérias e persistentes das regras, a possibilidade de expulsão do jogo;

3) A institucionalização de um papel específico que se mantém, por assim dizer, $<$ fora $>$ e $<$ acima $>$ do jogo e cuja tarefa é controle, isto é, o papel do <árbitro>;

4) Um órgão centralizado de caráter nacional, para elaboração das regras, a Rugby Football Union. (ELIAS 1992, p. 335/336).

ELIAS (2011, p. 67), se refere às regras de etiqueta inseridas no processo civilizador exigidas à época, pela alta sociedade de corte ou cortesã da Europa, em comparação com as exigências da etiqueta, disciplina e respeito hierárquico, aliadas, inclusive, às normas de higiene, exigidas no Karatê têm uma flagrante semelhança em sua aplicabilidade, nesse contexto de conduta humana e de processo social.

Assim, Elias cita Erasmos de Roterdam com seu tratado de 1530, De civilitatemorumpuerilium (da civilidade em crianças), documento que tratava do aprendizado de regras de comportamento no desenvolvimento do conceito de civilidade (civilité), com suas regras de comportamento, de boas maneiras, de comportamento de pessoas em suas relações com as outras, em sociedade, com referência à postura, ao gesto de respeito e ao vestuário, e ressalta

[...] a postura, o gesto, o vestuário, as expressões faciais - este comportamento 'externo' de que cuida o tratado é a manifestação do homem interior, inteiro [...]. Embora este decoro externo proceda de uma mente bem-constituída não obstante descobrimos às vezes que, por falta de instrução, essa graça falta em homens excelentes e cultos.(ELIAS 2011, p. 65). 


\section{CONSIDERAÇÕES FINAIS}

Aproximar as artes marciais, especialmente o Karatê, da teoria é um avanço. Passado entre gerações, quase sempre pela oralidade e pela prática, o Karatê ganha novos olhares científicos.

Na posição de $5^{\circ}$ Dan de Karatê e $3^{\circ}$ de Kobu-Do, me preparei e posteriormente preparei por quatro décadas e meia, crianças, jovens e adultos para valorizar suas determinações e para o convívio social.

Disciplina, arraigada nos princípios filosóficos orientaram minha docência no Karatê e no Kobu-Do. Potencializei as capacidades de homens e mulheres que se tornaram superiores fisicamente aos seus pares. Somei a essas capacidades as habilidades do Karatê, tornando seus membros fatais quando atingido com potência, em outro indivíduo. Mas, foi com o objetivo de formar o bom cidadão, autocontrolado e determinante no jogo social, que vi Karatekas se formarem.

\section{Referências}

ELIAS, Nobert; DUNNING, Eric. A busca da excitação. Lisboa: Difusão Editorial Ltda., 1992.

Elias, Norbert. O Processo Civilizador, vol. 1. Rio de Janeiro: Zahar Editores 1993.

. Escritos e Ensaios; In: Estado, Processo, opinião pública. Rio de Janeiro: Jorge Zahar Ed., 2006.

1994. - A Sociedade dos Indivíduos. Rio de Janeiro: Zahar Editores, - Envolvimento e alienação. Traduzido do inglês por Álvaro de Sá. - Rio de Janeiro: Bertrand Brasil, 1998.

FOUCAUT, Michel: Vigiar e punir: nascimento da prisão, Petrópolis, Vozes, 1977, disponível em catálogo coletivo - coleção biblioteca 2.senado.gov.br. 
Howard Reid e Michael Croucherin: The Way ofWarrior: The Paradoxo ofthe Marcial Arts - O Caminho do Guerreiro: o paradoxo das artes marciais, São Paulo, Editora Cultrix,1983.

Revista Shinshukan, Edição Especial de Aniversário, ano 1, nº 01, 2012.

Revista Grandes Mestres das Artes Marciais no Brasil, 6a Edição, 2014.

Revista SHINZATO, YOSHIHIDE. Kibon da União Shorin-RyuKarate-Do Brasil. São Carlos: Suprema, 2004.

\section{Outras Fontes}

História Oral registrada, enquanto aluno do Grão-Mestre Yoshihide Shinzato, décadas 70, 80, 90 e 2000, até antes de seu falecimento em 13.01.2008. 